\title{
Análise Microbiológica de Vegetais em Conserva Fracionados em Estabelecimentos Comerciais Para Venda A Granel, Na Zona Norte da Cidade do Rio de Janeiro
}

Camila Vicente Farias (I), Gabriella Araujo Rebouças Oliveira (I), Thaís Campos Alves (I), Thaís Souza Silveira (I), Janaína dos Santos Nascimento (I), Leonardo Emanuel de Oliveira Costa (I), Barbara Cristina Euzebio Pereira Dias de Oliveira (I,II)

(I) IFRJ - Instituto Federal de Educação do Rio de Janeiro (Rua Senador Furtado, 121, Maracanã. Rio de Janeiro/RJ, Brasil. CEP: 20270-021), (II) LABPAT/IOC/Fiocruz - Laboratório de Patologia - Instituto Oswaldo Cruz/Fiocruz (Av Brasil 4365, Pav Gomes de F Faria Manguinhos - Rio de Janeiro - 21040-360)

\section{Resumo}

Os alimentos de origem vegetal, frescos ou processados, podem veicular diversos micro-organismos patogênicos. Estes alimentos que, eventualmente, estejam contaminados, ao serem ingeridos, permitem que os patógenos ou os seus metabólitos invadam os fluídos ou os tecidos do hospedeiro podendo causar doenças graves. $\mathrm{O}$ objetivo do presente trabalho foi realizar a análise microbiológica de vegetais em conserva que são fracionados na unidade de comercialização para venda a granel. Estes produtos são abertos e manipulados no local de venda, quebrando a segurança da cadeia produtiva por inserir uma manipulação a mais do produto, realizada após a saída da indústria e antes de chegar à mesa do consumidor. Foram analisadas amostras de $50 \mathrm{~g}$ de diferentes vegetais em conserva obtidas de estabelecimentos da Zona Norte da cidade do Rio de Janeiro. As análises realizadas seguiram o regulamento técnico sobre padrões microbiológicos para alimentos no Brasil (RDC $\mathrm{n}^{\circ} .12 \mathrm{de}$ 2/01/2001). A partir das amostras, foram analisados coliformes totais e termotolerantes quantificados pelas técnicas de número mais provável

\footnotetext{
Referência:

Camila Vicente Farias, Gabriella Araujo Rebouças Oliveira, Thaís Campos Alves, Thaís Souza Silveira, Janaína dos Santos Nascimento, Leonardo Emanuel de Oliveira Costa, Barbara Cristina Euzebio Pereira Dias de Oliveira. Análise Microbiológica de Vegetais em Conserva Fracionados em Estabelecimentos Comerciais Para Venda A Granel, Na Zona Norte da Cidade do Rio de Janeiro. In: Anais do 12 Congresso Latinoamericano de Microbiologia e Higiene de Alimentos - MICROAL 2014 [= Blucher Food Science Proceedings, num.1, vol.1]. São Paulo: Editora Blucher, 2014.

DOI 10.5151/foodsci-microal-176
} 
(NMP) e realizada a quantificação de bactérias mesófilas pelo método de "pour plate" em ágar PCA; de bolores e leveduras, e de Estafilocococos coagulase positivo (ECP), pelo método "spread plate" em Ágar PDA e Baird-Parker, respectivamente. Para a análise de Salmonella spp. foi feito o pré-enriquecimento em água peptonada $1 \%$ seguido do enriquecimento seletivo nos caldos RV, SC e TT, com posterior isolamento nos ágares XLD, Rambach e Bismuto Sulfito. Para as colônias típicas foram realizados testes bioquímicos, sendo todos estes realizados segundo a Instrução Normativa 62. Até o momento foram obtidas 33 amostras de 11 estabelecimentos comerciais. A maioria das amostras analisadas pode ser considerada segura para o consumidor, apesar de terem sido detectados leveduras e micro-organismos aeróbios mesófilos (valores entre $10^{3}$ e $10^{4}$ UFC/g de amostra). Não foi detectada a presença de ECP em nenhuma das amostras analisadas. Quanto à análise de Salmonella, foram obtidas duas colônias positivas em uma amostra, confirmadas no teste de soroaglutinação. A presença de Salmonella sp. em uma amostra indica que esta estava imprópria para o consumo humano representando um risco para a saúde do consumidor.

Palavras-Chave: coliformes, comercio varejista, manipulação de alimentos, Salmonella, vegetais em conserva Agência de Fomento: IFRJ, FAPERJ e CNPq 